\title{
Understanding of Diabetic Dyslipidemia by Using the Anion- Exchange High Performance Liquid Chromatography Data
}

\author{
Hidekatsu Yanaia, h, Yuji Hirowatari $^{\mathrm{b}}$, Kumie Ito ${ }^{\mathrm{c}}$, Hideo Kurosawa ${ }^{\mathrm{d}, ~ e}$, Norio Tada ${ }^{\mathrm{d}}$, \\ Hiroshi Yoshida ${ }^{\mathrm{d}, \mathrm{f}, \mathrm{g}}$
}

\section{To the Editor}

Type 2 diabetes and dyslipidemia are cardiovascular risk factors which should be managed [1]. However, the precise lipoprotein profiles and the underlying mechanisms for diabetic dyslipidemia remain largely unknown. We previously developed an anion-exchange liquid chromatographic method (AEX-HPLC) which can measure cholesterol levels of triglyceride (TG)-rich lipoproteins such as very low-density lipoprotein (VLDL), intermediate-density lipoprotein (IDL) and chylomicron (CM) in addition to low-density lipoprotein (LDL) and high-density lipoprotein (HDL) [2]. Here we compared lipoprotein profiles obtained by our previous studies using AEX-HPLC in young lean men [3], subjects with low Framingham risk score (FRS) $[4,5]$, type 2 diabetic patients without obesity and type 2 diabetic patients with obesity [6,7].

The mean \pm SD values of age, body mass index, HbAlc in in young lean men $(n=7)$ [3], low FRS subjects $(n=304)$ [4], type 2 diabetic patients without obesity $(n=194)$ [6], and type 2 diabetic patients with obesity $(n=5)$ [7] were $24 \pm 2,51$ $\pm 8,63 \pm 13$, and $60 \pm 9$ years old, $20.8 \pm 2.2,23.8 \pm 3.0,23.1$ \pm 2.0 , and $29.5 \pm 7.0 \mathrm{~kg} / \mathrm{m}^{2}, 5.0 \pm 0.2,5.4 \pm 0.5,6.3 \pm 1.0$, and $9.1 \pm 2.1 \%$, respectively.

HDL-cholesterol (HDL-C) in type 2 diabetes $(49.9 \pm 16.6$ $\mathrm{mg} / \mathrm{dL}(1.29 \pm 0.43 \mathrm{mmol} / \mathrm{L}))$, especially in type 2 diabetic

Manuscript accepted for publication March 03, 2016

aDepartment of Internal Medicine, National Center for Global Health and Medicine Kohnodai Hospital, Chiba, Japan

bLaboratory Sciences, Department of Health Sciences, School of Health and Social Service, Saitama Prefectural University, Saitama, Japan

'Department of Internal Medicine, Yaesu Sakura Dori Clinic, Tokyo, Japan

dInstitute of Clinical Medicine and Research, Jikei University School of Medicine, Chiba, Japan

eDepartment of Laboratory Medicine, Inzai General Hospital, Chiba, Japan fDepartment of Internal Medicine, Jikei University Kashiwa Hospital, Chiba, Japan

gDepartment of Laboratory Medicine, Jikei University Kashiwa Hospital, Chiba, Japan

${ }^{\mathrm{h}}$ Corresponding Author: Hidekatsu Yanai, Department of Internal Medicine, National Center for Global Health and Medicine Kohnodai Hospital. 1-7-1 Kohnodai, Ichikawa, Chiba 272-0034, Japan.

Email: dyanai@hospk.ncgm.go.jp

doi: http://dx.doi.org/10.14740/jocmr2533w patients with obesity $(36.4 \pm 5.3 \mathrm{mg} / \mathrm{dL}(0.94 \pm 0.14 \mathrm{mmol} / \mathrm{L}))$ was lower than young lean men $(59.4 \pm 10.1 \mathrm{mg} / \mathrm{dL}(1.54 \pm$ $0.26 \mathrm{mmol} / \mathrm{L}))$ and low FRS subjects $(57.6 \pm 14.7 \mathrm{mg} / \mathrm{dL}(1.49$ $\pm 0.38 \mathrm{mmol} / \mathrm{L})$ ). IDL-C in type 2 diabetes was higher than other two groups, and IDL-C was higher in the order of type 2 diabetic patients with obesity $(9.8 \pm 3.0 \mathrm{mg} / \mathrm{dL}(0.25 \pm 0.08$ $\mathrm{mmol} / \mathrm{L})$ ), type 2 diabetic patients without obesity $(9.3 \pm 4.6$ $\mathrm{mg} / \mathrm{dL}(0.24 \pm 0.12 \mathrm{mmol} / \mathrm{L}))$, low FRS subjects $(7.3 \pm 3.1 \mathrm{mg} /$ $\mathrm{dL}(0.19 \pm 0.08 \mathrm{mmol} / \mathrm{L}))$, young lean men $(4.3 \pm 2.2 \mathrm{mg} / \mathrm{dL}$ $(0.11 \pm 0.06 \mathrm{mmol} / \mathrm{L}))$. VLDL-C clearly showed higher values in the order of type 2 diabetic patients with obesity (27.3 \pm $22.7 \mathrm{mg} / \mathrm{dL}(0.71 \pm 0.59 \mathrm{mmol} / \mathrm{L}))$, type 2 diabetic patients without obesity $(20.1 \pm 16.2 \mathrm{mg} / \mathrm{dL}(0.52 \pm 0.42 \mathrm{mmol} / \mathrm{L}))$, low FRS subjects $(16.6 \pm 12.8 \mathrm{mg} / \mathrm{dL}(0.43 \pm 0.33 \mathrm{mmol} / \mathrm{L}))$, and young lean men $(4.0 \pm 4.6 \mathrm{mg} / \mathrm{dL}(0.10 \pm 0.12 \mathrm{mmol} / \mathrm{L}))$. LDL-C and CM-C did not show the characteristic profile for diabetes.

According to accumulation of our previous AEX-HPLC data $[3,4,6,7]$, the characteristics in diabetic dyslipidemia is reduced HDL-C, and increased IDL-C and VLDL-C, which is further deteriorated by complication with obesity. Relative insulin deficiency due to insulin resistance increases activity and expression of hormone-sensitive lipase (HSL) in adipose tissue, which catalyzes the breakdown of TG, releasing free fatty acids (FFA) (Fig. 1) [8]. Insulin promotes apoB100 degradation, and hepatic insulin resistance causes reduction of apoB100 degradation [9]. Insulin resistance also induces an enhanced expression of microsomal TG transfer protein (MTP), a key enzyme involved in VLDL assembly [10]. In type 2 diabetes, increased FFA entry to liver, reduced degradation of apoB100 and enhanced expression of MTP may elevate hepatic production of VLDL. Relative insulin deficiency also decreases the activity of lipoprotein lipase (LPL), the rate-limiting enzyme of the catabolism of TG-rich lipoproteins such as CM, VLDL and IDL [11]. The formation of HDL is related with the catabolism of TG-rich lipoproteins by LPL [12]. Therefore, reduced LPL activity increases IDL and VLDL, and reduces HDL. The activity of hepatic TG lipase (HTGL), the enzyme that facilitates the catabolism of HDL, is correlated with insulin requirement [13]. In type 2 diabetes, low serum HDL-C may be partially due to an increased rate of clearance by HTGL [13]. LDL size and buoyancy are inversely proportional to HTGL activity [14], and patients with high HTGL have smaller, denser LDL particles, as compared with subjects with low HTGL activity [15]. Increased HTGL activity due 


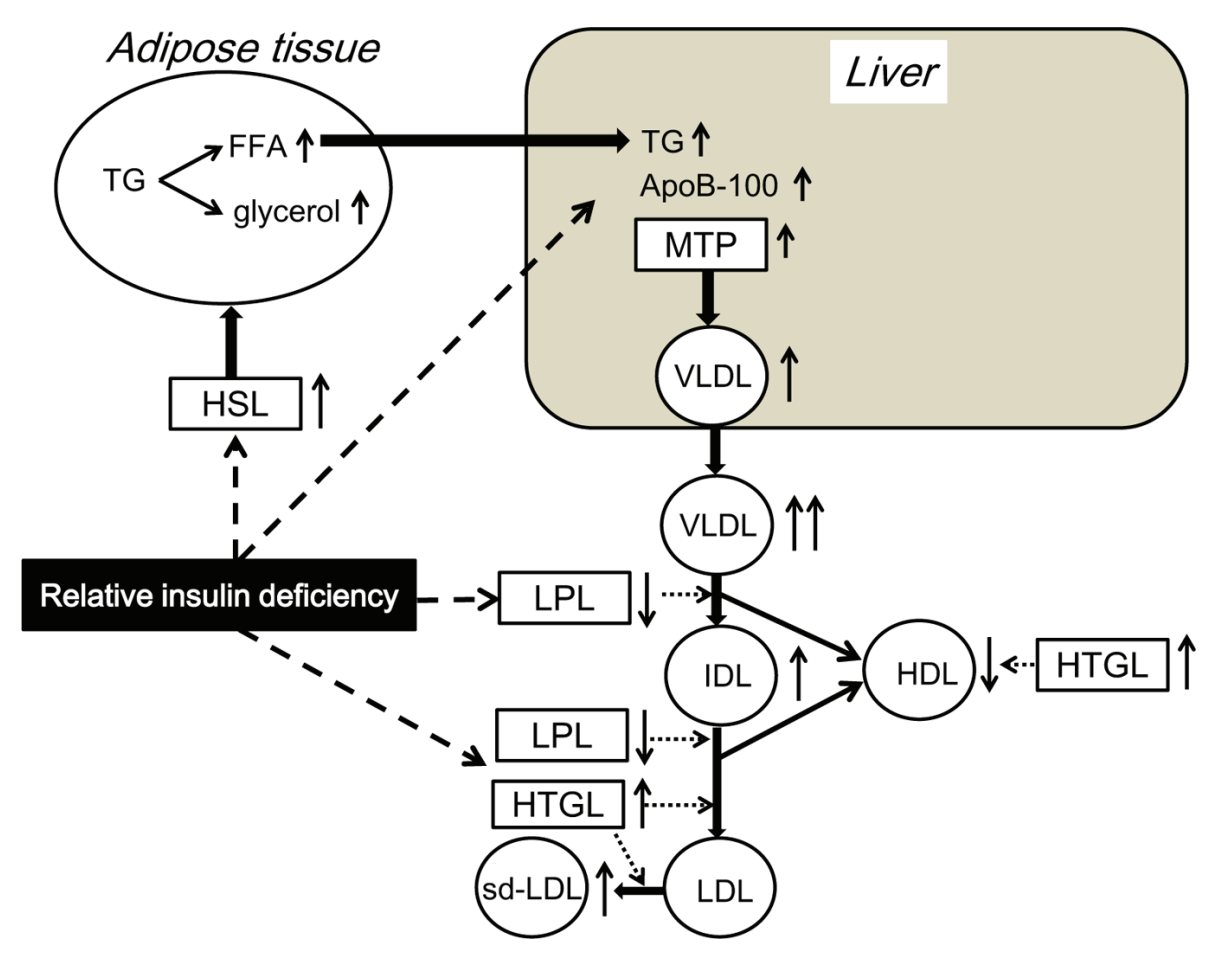

Figure 1. The underlying mechanisms for development of diabetic dyslipidemia. FFA: free fatty acids; HDL: high-density lipoprotein; HSL: hormone-sensitive lipase; HTGL: hepatic triglyceride lipase; IDL: intermediate-density lipoprotein; LDL: Iow-density lipoprotein; LPL: lipoprotein lipase; MTP: microsomal triglyceride transfer protein; sd-LDL: small dense LDL; TG: triglyceride; VLDL: very low-density lipoprotein.

to insulin resistance/relative insulin deficiency may increase small dense LDL, atherogenic lipoprotein, in type 2 diabetes.

In conclusion, accumulation of our previous AEX-HPLC data provided us the characteristics for diabetic dyslipidemia such as reduced HDL-C, and increased IDL-C and VLDL-C, which is further deteriorated by complication with obesity. Disturbed regulation in activity and expression of HSL, apoB100, MTP, LPL and HTGL due to insulin resistance/relative insulin deficiency may induce diabetic dyslipidemia.

\section{References}

1. Levine JH. Managing multiple cardiovascular risk factors: state of the science. J Clin Hypertens (Greenwich). 2006;8(10 Suppl 3):12-22.

2. Hirowatari Y, Yoshida H, Kurosawa H, Doumitu KI, Tada N. Measurement of cholesterol of major serum lipoprotein classes by anion-exchange HPLC with perchlorate ion-containing eluent. J Lipid Res. 2003;44(7):14041412.

3. Yanai H, Yoshida H, Tomono Y, Hirowatari Y, Kurosawa H, Matsumoto A, Tada N. Effects of diacylglycerol on glucose, lipid metabolism, and plasma serotonin levels in lean Japanese. Obesity (Silver Spring). 2008;16(1):47-51.

4. Ito K, Yoshida H, Yanai H, Kurosawa H, Sato R, Manita D, Hirowatari Y, et al. Relevance of intermediate-density lipoprotein cholesterol to Framingham risk score of coronary heart disease in middle-aged men with increased
non-HDL cholesterol. Int J Cardiol. 2013;168(4):38533858.

5. Wilson PW, D'Agostino RB, Levy D, Belanger AM, Silbershatz H, Kannel WB. Prediction of coronary heart disease using risk factor categories. Circulation. 1998;97(18):1837-1847.

6. Yoshida H, Hirowatari Y, Kurosawa H, Manita D, Yanai $\mathrm{H}$, Ito $\mathrm{K}$, Tada $\mathrm{N}$. Estimation of lipoprotein profile in patients with type II diabetes and its relevance to remnant lipoprotein cholesterol levels. Atherosclerosis. 2012;222(2):541-544.

7. Yanai H, Hamasaki H, Adachi H, Moriyama S, Hirowatari Y. Effects of liraglutide, a human glucagon-like peptide-1 analog, on glucose/lipid metabolism, and adipocytokines in patients with type 2 diabetes. J Endocrinol Metab. 2011;1(3):149-151.

8. Sztalryd C, Kraemer FB. Regulation of hormone-sensitive lipase in streptozotocin-induced diabetic rats. Metabolism. 1995;44(11):1391-1396.

9. Fisher EA. The degradation of apolipoprotein B100: multiple opportunities to regulate VLDL triglyceride production by different proteolytic pathways. Biochim Biophys Acta. 2012;1821(5):778-781.

10. Taghibiglou C, Carpentier A, Van Iderstine SC, Chen B, Rudy D, Aiton A, Lewis GF, et al. Mechanisms of hepatic very low density lipoprotein overproduction in insulin resistance. Evidence for enhanced lipoprotein assembly, reduced intracellular ApoB degradation, and increased microsomal triglyceride transfer protein in a fructose-fed 
hamster model. J Biol Chem. 2000;275(12):8416-8425.

11. Nikkila EA, Huttunen JK, Ehnholm C. Postheparin plasma lipoprotein lipase and hepatic lipase in diabetes mellitus. Relationship to plasma triglyceride metabolism. Diabetes. 1977;26(1):11-21.

12. Nikkila EA, Taskinen MR, Kekki M. Relation of plasma high-density lipoprotein cholesterol to lipoprotein-lipase activity in adipose tissue and skeletal muscle of man. Atherosclerosis. 1978;29(4):497-501.

13. Kasim SE, Tseng K, Jen KL, Khilnani S. Significance of hepatic triglyceride lipase activity in the regulation of serum high density lipoproteins in type II diabetes mellitus. J Clin Endocrinol Metab. 1987;65(1):183-187.

14. Vega GL, Grundy SM. Effect of statins on metabolism of apo-B-containing lipoproteins in hypertriglyceridemic men. Am J Cardiol. 1998;81(4A):36B-42B.

15. Zambon A, Austin MA, Brown BG, Hokanson JE, Brunzell JD. Effect of hepatic lipase on LDL in normal men and those with coronary artery disease. Arterioscler Thromb. 1993;13(2):147-153. 